http://doi.org/10.21555/top.v0i58.1061

Not-being, Falsehood and Contradiction: the Second Eristic Demonstration of the Euthydemus and the Problem of the False in the Sophist

\title{
No-ser, falsedad y contradicción: la segunda demostración erística del Eutidemo y el problema de lo falso en el Sofista
}

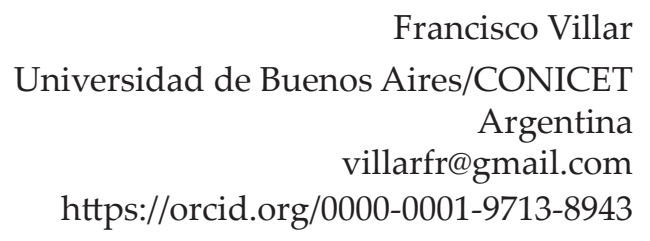

Recibido: 01 - 05 - 2018.

Aceptado:16 - 08 - 2018.

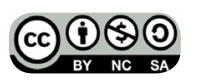

This work is licensed under a Creative Commons Attribution

-NonCommercial-ShareAlike 4.0 International License. 


\begin{abstract}
This work proposes an interpretation of Euthydemus $283 \mathrm{c}-288 \mathrm{~b}$ taking into account the problem of the false in the Sophist. My hypothesis will be that the second eristic demonstration of the Euthydemus can be understood as a representation of Sophist 236d-239b: while in this passage there it is the Stranger is the one who states what the sophist would say to defend himself from the seventh definition, in which he is accused of producing falsehoods, in the Euthydemus two sophists are who use the notions of non-being and falsehood to refute such accusation. The work has three parts. Firstly, I shall analyze Sophist 236d-239b and contextualize it within the framework of the seventh definition. Secondly, I focus on the characterization of Euthydemus and Dionysodorus as sophists. Finally, I analyze the three arguments that organize the second demonstration of the Euthydemus, trying to understand its structure and its role in the drama of the dialogue.

Keywords: not-being; falsehood; sophists; Sophist; Euthydemus.
\end{abstract}

\title{
Resumen
}

Este trabajo lleva a cabo una lectura de Eutidemo 283c-288b a la luz del problema de la falsedad en el Sofista. Mi hipótesis será que la segunda demostración erística del Eutidemo puede ser interpretada como una representación de Sofista 236d-239b: mientras que allí es el Extranjero el que evoca lo que el sofista diría para defenderse de la séptima definición, donde se le acusa de producir falsedades, en el Eutidemo son dos sofistas quienes emplean las nociones de no-ser y falsedad para refutar dicha acusación. La exposición tendrá tres partes. En la primera analizaré Sofista 236d-239b y lo contextualizaré en el marco de la séptima definición. En la segunda me concentraré en la caracterización de Eutidemo y Dionisodoro en tanto sofistas. En la tercera analizaré los tres argumentos que organizan la segunda demostración del Eutidemo, intentando dar cuenta de su estructura y su rol en la economía dramática del diálogo.

Palabras clave: no-ser; falsedad; sofistas; Sofista; Eutidemo. 
El problema en torno a la imposibilidad de dar una explicación de los juicios falsos es un asunto que atraviesa gran parte de la obra platónica. Esta posición, con la cual Platón polemizó, podría sintetizarse del siguiente modo: si lo falso consiste en decir lo que no es, entonces no es posible decir cosas falsas, puesto que lo que no es no existe. Si un discurso dice algo, por tanto, dice algo que es, es decir, cosas verdaderas. Si bien se debe esperar a un diálogo de vejez como el Sofista para hallar un tratamiento acabado de esta cuestión, Platón ya había tematizado la dificultad en escritos más tempranos, como Crátilo (cfr. 429c-429e), Eutidemo (cfr. 283c-288b) y Teeteto (cfr. 187a-201c).

El interés platónico por el argumento podría deberse a que efectivamente fue defendido por intelectuales de su contexto de producción. Antístenes, por ejemplo, sostenía que no es posible contradecir (SSR V.A. 152-156), esto es, que dos personas expresen enunciados que se opongan respecto de su verdad y falsedad. A pesar de que probablemente fue este socrático quien más difundió tal punto de vista en el siglo IV a. C., el tópico excede su figura. Testimonio de esto es Platón mismo, quien insiste en la antigüedad del argumento (cfr. Cra. 429d y Euthd. 286c) y lo vincula con pensadores del siglo V a. C., ya sea directamente, como Protágoras (cfr. Euthd. 286c), o indirectamente, como Parménides (cfr. Soph. 237a). Ambas referencias son importantes, ya que permiten conectar dos textos cercanos en lo que respecta a cómo Platón presenta la dificultad. ${ }^{1}$

El problema de la falsedad en el Sofista (cfr. 236d-264c) se enmarca en la última definición del personaje homónimo. En ella se intenta definir a esta figura en tanto poseedor de una técnica que produce apariencias, cosas que aparentan parecerse a lo real sin hacerlo verdaderamente. Es esta caracterización la que desemboca en la paradoja: frente a tal acusación, el sofista se escudará en que no es posible decir cosas falsas, dado que eso implica sostener que existe lo que no es, lo cual va en contra de lo establecido por Parménides. Aunque el sofista aquí no se

1 Si bien no desconocemos el entramado dialógico en el cual se inserta el tratamiento platónico de esta temática, aquí consideraremos sólo Eutidemo y Sofista. Para un análisis de las distintas posturas respecto de qué figuras históricas y qué posiciones teóricas circundan al problema del error en Platón, principalmente en Sofista, cfr. Sonna, 2017. Sobre la formulación del Teeteto, cfr. Marcos, 1995, pp. 17-96. 
halla presente, habla a través del Extranjero de Elea, quien en 236d-239b muestra las dificultades que las nociones de no-ser y falsedad presentan para aquel que intenta acusar a otro de decir algo falso.

Este pasaje no es el único en el cual Platón retrata a un sofista en una actitud similar. La segunda demostración erística del Eutidemo (cfr. 283c-288b) constituye un antecedente de esta estrategia. Allí los hermanos Eutidemo y Dionisodoro desarrollan una serie de razonamientos que tienen como fin socavar la posibilidad de que alguien atribuya a otro el acto de mentir, decir falsedades o contradecir a otro. Además de compartir el mismo propósito, la argumentación de los erísticos reviste un gran parecido de familia con la del Sofista, dado que lo falso es ligado a una noción absoluta o existencial del no-ser que da lugar a múltiples inconvenientes y paradojas.

Este trabajo se propone realizar una lectura de Eutidemo 283c-288b a la luz del desarrollo del problema de la imposibilidad de lo falso en el Sofista. Mi hipótesis será que la segunda demostración erística del Eutidemo puede ser interpretada como una representación vívida de Sofista 236d-239b: mientras que en el Sofista es el Extranjero el que evoca lo que el sofista diría en su defensa, en el Eutidemo son dos sofistas quienes hacen uso de las nociones de no-ser y falsedad para refutar la acusación. Considero que esta propuesta de lectura permite vincular aún más estrechamente los dos diálogos, ya que los argumentos presentados en ellos comparten no sólo cuestiones doctrinales, señaladas a menudo por los especialistas, sino también defensores con características similares que, asimismo, hacen uso de la misma estrategia para dar con su enunciación.

La exposición constará de tres partes. En la primera haré un breve paso por el Sofista a fin de examinar el pasaje 236d-239b y contextualizarlo en el marco de la séptima definición. En la segunda me concentraré en la caracterización de Eutidemo y Dionisodoro en tanto sofistas, procurando ver cómo estos podrían caer bajo este concepto. En la tercera, finalmente, analizaré los tres argumentos que organizan la segunda demostración erística del Eutidemo, intentando dar cuenta de dos elementos: por un lado, su estructura y contenido, lo cual permitiría vincularlos con la temática del Sofista; por otro, su rol en la economía dramática del diálogo, aspecto que haría posible interpretarlos como una instanciación de la estrategia argumentativa del sofista. 


\section{I}

Si bien la unidad temática del Sofista ha despertado dudas lo largo de la historia, hay un tema central que estructura la obra: la definición del sofista. ${ }^{2}$ Las controversias sobre este punto se deben a la interrupción de dicho propósito en $237 \mathrm{~b}$, donde se da inicio a una extensa digresión (cfr. 237b-264c). No obstante, esta desviación no está desvinculada del resto del diálogo, puesto que hace su aparición en el transcurso de la última definición. Ésta, la séptima que el Extranjero y Teeteto elaboran, ${ }^{3}$ comienza con una caracterización preliminar (cfr. 232a-233d) del sofista

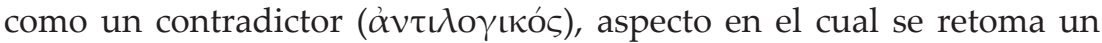
elemento de la quinta (cfr. 225a-226a y 231e), donde se lo define como

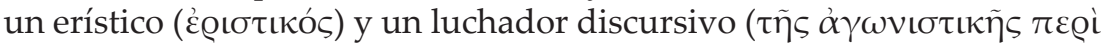

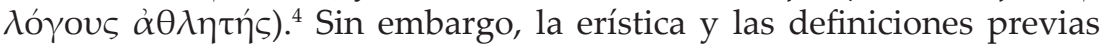

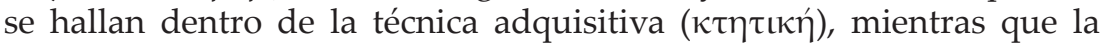
séptima implica un cambio de perspectiva, en tanto que el sofista es situado en la producción (cfr. 233d). ${ }^{5}$

Antes de toparse con el problema de la falsedad, el Extranjero y Teeteto realizan dos divisiones. En primer lugar (cfr. 233d-235c), al

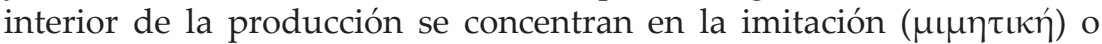

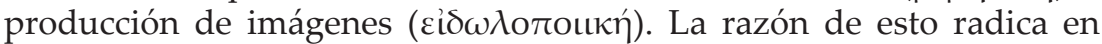
que caracterizan al sofista como alguien que se presenta como capaz de

2 Para una discusión acerca del tema del diálogo y una defensa de esta postura, cfr. Notomi, 1999, pp. 1-42.

3 Para una reconstrucción del método definicional de reunión y división, cfr. Sayre, 2006, el cual incluye, además, un desglose de todas las divisiones que comprenden las siete definiciones del Sofista (pp. 55-73).

4 Hemos empleado los textos griegos establecidos por Méridier (1931) y Burnet (1995). Las traducciones citadas del Sofista pertenecen a Cordero (1988). En cuanto al Eutidemo, en líneas generales hemos seguido la traducción de Mársico e Inverso (2012), aunque con ligeras modificaciones.

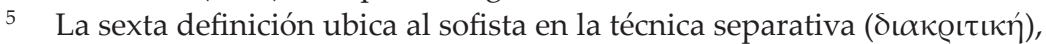
la cual podría ser distinta de la adquisitiva y la productiva (cfr. Cornford, 1935, pp. 177-178; Cordero, 1988, p. 44 y Sayre, 2006, p. 66). Rickless (2010) defiende que las dos últimas definiciones operan con la producción como género inicial: la sexta definiría a la sofística como un arte separativa, mientras que la séptima como un arte combinativa. 
producir todas las cosas con su técnica, una especie de mago o ilusionista que, empleando imágenes habladas ( $\varepsilon$ ľ $\delta \omega \lambda \alpha \lambda \varepsilon \gamma$ ó $\mu \varepsilon v \alpha)$, hechiza a los oyentes y les hace creer que lo que dice es lo real. En segundo lugar (cfr. 235c-236d), la técnica de hacer imágenes es dividida en figurativa

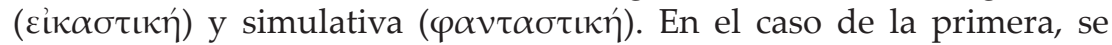
trataría de un tipo de imitación que atiende a las proporciones y colores reales de lo imitado. La segunda, por el contrario, no realiza algo que se parezca a su modelo, sino algo que sólo aparenta parecerse, es decir, una apariencia $(\varphi \alpha ́ v \tau \alpha \sigma \mu \alpha)$.

Es aquí donde se señala que el sofista se ha refugiado en un lugar complejo:

Estamos frente a un examen extremadamente difícil,

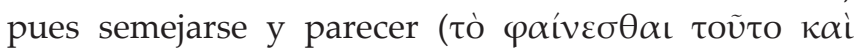

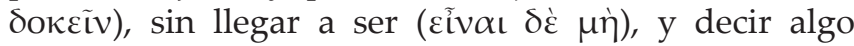

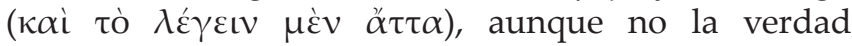
$(\dot{\alpha} \lambda \eta \theta \tilde{\eta} \delta \dot{\varepsilon} \mu \eta \dot{)})$, son conceptos, todos ellos ( $\pi \alpha \dot{\alpha} v \tau \alpha$ $\tau \alpha \tilde{v} \tau \alpha)$, que están siempre llenos de dificultades ( $\dot{\varepsilon} \sigma \tau \iota \mu \varepsilon \sigma \tau \dot{\alpha} \dot{\alpha} \pi \mathrm{o} \iota \alpha \varsigma \dot{\alpha} \varepsilon \dot{\imath})$, tanto antiguamente como ahora. Pues afirmar que realmente se pueden decir y

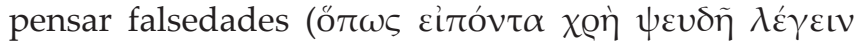

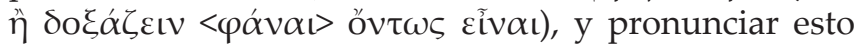
sin incurrir necesariamente en una contradicción ( $\kappa \alpha i$

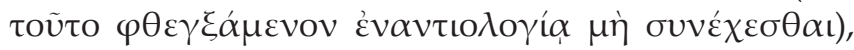
es, Teeteto, enormemente difícil (Platón, Sofista 236d).

De este texto nos interesa destacar tres elementos. Por un lado, la acotación de la apariencia al ámbito lingüístico, algo coherente con el marco problemático de la séptima definición, donde el sofista elaboraba "imágenes habladas" (234c). Por otro, la asimilación de la apariencia con la falsedad o, más propiamente, la de "producir algo que parece ser pero no es" con "decir algo que no es verdadero". Dado que el decir es entendido como un producir, el sofista es un productor de un discurso no verdadero. Finalmente, el señalamiento de un inconveniente en el cual caería cualquiera que impute a otro la producción de tal tipo de discurso: dicha acusación implica sostener que se pueden decir y pensar falsedades, afirmación que envuelve una contradicción.

Esta última se construye con base en dos supuestos explicitados en 237a: la asociación entre no-ser y falsedad y la enunciación de la tesis de Parménides. Respecto del primer punto, el Extranjero subraya que 
afirmar la posibilidad de la falsedad implica sostener que existe lo que

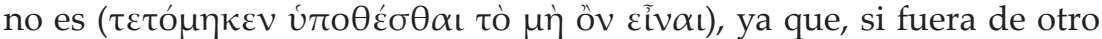
modo (ä $\lambda \lambda \omega \varsigma)$-a saber, que no exista-, la falsedad no podría llegar

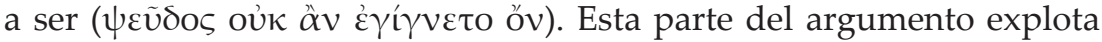
un hecho de lengua propio del griego. El verbo عĩval, en efecto, posee varios usos y matices. Para enunciar que Sócrates existe, que es bueno,

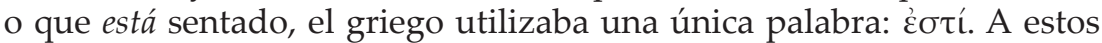
empleos hay que sumar un importante uso veritativo, donde el verbo significa "ser el caso" o "ser verdadero". La utilización de los participios

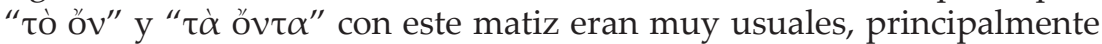
dependiendo de verbos de decir. Es por esto que "decir cosas que son"

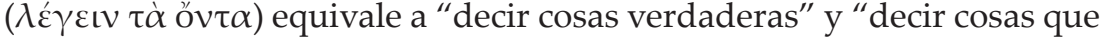
no son" ( $\lambda \varepsilon ́ \gamma \varepsilon เ \nu \tau \dot{\alpha} \mu \eta \dot{~ o ́ v \tau \alpha) ~ a ~ " d e c i r ~ c o s a s ~ f a l s a s " . ~}{ }^{6}$

La autoridad de Parménides, no obstante, es invocada para poner al descubierto el camino sin salida en el que cae dicha caracterización de la falsedad, puesto que éste había censurado afirmar que "hay cosas que no son $(\varepsilon \tilde{\tau} v \alpha \iota \mu \eta \dot{~ \varepsilon ́ o ́ v \tau} \alpha)^{\prime \prime}{ }^{7}$ Esta tesis es la que permite hacer explícita la contradicción: si, por un lado, la falsedad es decir cosas que no son y, por otro, las cosas que no son no existen, entonces no es posible defender que se pueda producir un discurso falso. Aunque, como veremos, más elementos serán añadidos al argumento, esta concisa formulación alcanza para hacer inteligible la estrategia empleada por el sofista para defenderse de la séptima definición.

En 237b-242a el Extranjero y Teeteto analizarán más aristas del problema y llegarán a la conclusión de que es necesario el parricidio de Parménides, esto es, "obligar a lo que no es, a que en cierto modo sea, y, recíprocamente, a lo que es, a que en cierto modo no sea" (241d), dando inicio a la parte más constructiva de la obra. En vistas a nuestro propósito de examinar la formulación del Eutidemo, nos detendremos sólo en la "analítica del no-ser" (237b-239c), sección dedicada a indagar tres problemas que afectarían a "lo que no es de ningún modo (

6 Para un análisis exhaustivo de los usos de عĩvaı en griego clásico, cfr. Kahn (2003), especialmente las secciones dedicadas al uso veritativo (pp. 331370) y a las construcciones de participio sustantivado (pp. 453-457). Para un examen más conciso, cfr. la entrada de "cỉuí en Lidell, Scott y Jones (1996).

7 Sobre la posición de Parménides en el marco del Sofista y una evaluación del supuesto parricidio del eléata que Platón dice llevar a cabo (241d), cfr. Bossi (2013) y O’Brien (2013). 
$\mu \eta \delta \alpha \mu \tilde{\omega} \varsigma$ őv)", expresión con la cual el Extranjero refiere de una manera más enfática al no-ser empleado por el sofista. ${ }^{8}$

La primera dificultad (237b-237e) radica en el intento de considerar a "lo que no es" no como una mera cadena de sonidos, sino en tanto nombre (övo $\mu \alpha)$, procurando establecer a qué cosa debe aplicarse

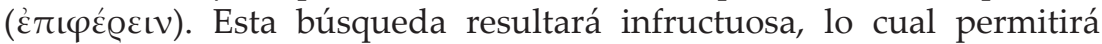
concluir en 237e que quien pronuncia ( $\varphi \theta \varepsilon \dot{\gamma} \gamma \varepsilon \sigma \theta \alpha \mathrm{s})$ "lo que no es", en realidad no dice nada $(\lambda \varepsilon \dot{\varepsilon} \gamma \varepsilon v \mu \eta \delta \varepsilon \dot{\varepsilon} \nu)$ y, más aún, ni siquiera debe

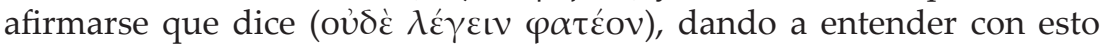
que quien enuncia "lo que no es" solamente arroja sonidos al vacío, sin expresar ninguna realidad extralingüística.

Para llegar a este resultado se analizan algunos candidatos a ocupar el rol de denotados por "lo que no es". Primero se descarta como una obviedad que pueda referir a las cosas que son ( $\tau \tilde{\omega} \nu \nu$ óv $\tau \omega \nu)$. Sin embargo, esto habilita un segundo inconveniente, ya que si no se aplica a lo que es, tampoco podría aplicarse a algo $(\tau \iota)$, ya que la palabra "algo" la utilizamos siempre respecto de algo que es ( $\dot{\varepsilon} \pi^{\prime}$ ' óv $\left.\tau \iota\right)$. El Extranjero añade, además, que si alguien dice algo $(\tau \iota)$, es necesario que diga algo único ( $\left.\varepsilon^{\prime} v \tau \iota\right)$. Es esta mención a la unidad la que hace posible que "lo que no es" no constituya un genuino nombre y que pronunciarlo sea

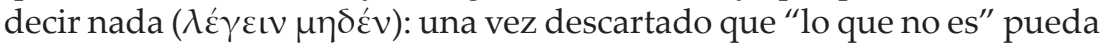
referir a algo, el acto de proferir este supuesto nombre es homologado al de decir "no-algo $(\mu \eta$ - $\tau \iota)$ ", expresión que el Extranjero hace equivaler a "nada $(\mu \eta-\delta \varepsilon ́ v)$ ", amparado en que la palabra "nada" en griego clásico se construye a partir de la negación del numeral ع̌v, el cual, según el argumento, estaba implicado por el $\tau$.

La segunda dificultad (238a-238c) señala la inconsistencia que conlleva añadirle a "lo que no es" el número, algo que, sin embargo, es necesario para pronunciarlo o pensarlo. El número, en efecto, está entre las cosas que son y, aunque no hay problema en agregar algo que es a otra cosa que es, sí debería ser imposible añadir algo que es a algo que no es. No obstante, para hablar o pensar acerca de "algo que no es" y de "las cosas que no son", hacemos uso de la unidad y la pluralidad, acto en el cual estaríamos agregando lo que es a lo que no es. La conclusión que saca el Extranjero es que no podemos ni pronunciar $(\varphi \theta \dot{\varepsilon} \gamma \xi \alpha \sigma \theta \alpha \iota)$

8 Dado que la apariencia y la imagen no son tematizados en el Eutidemo, los hemos dejado de lado, sin desconocer la relación de ambos conceptos con el problema de la falsedad, cfr. Notomi (1999, pp. 163-204). 


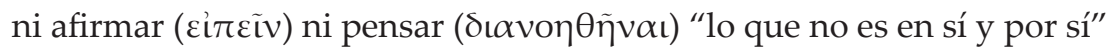

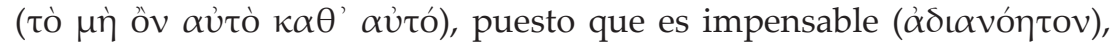

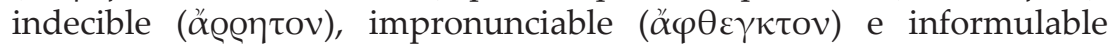

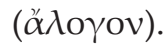

La tercera dificultad (238d-239b) busca extraer una consecuencia de la anterior y se centra en quien pretende realizar una refutación del noser, como cuando se intenta negar que "lo que no es" sea pronunciable, pensable, uno, múltiple, etc. El problema sería que cuando alguien se propone refutar ( $\dot{\varepsilon} \hat{\varepsilon} \gamma \chi \varepsilon เ v)$ a lo que no es, se ve obligado a afirmar lo contrario de lo que pretendía. Por un lado, si alguien quisiera defender que lo que no es no participa ni de la unidad ni de la pluralidad, está forzado a enunciarlo como uno, ya que debe hablar de "lo que no es". Por otro, al decir que es impronunciable, indecible e informulable, debe

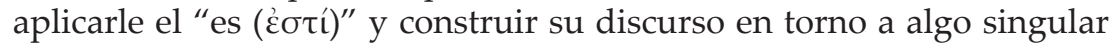
y único. El extranjero concluye, finalmente, que si se quiere hablar con total corrección (o@ $\theta \tilde{\omega} \varsigma)$, no se debe ni definir a lo que no es ni como uno ni como múltiple, ni llamarlo ( $\kappa \alpha \lambda \varepsilon \tilde{\imath} v)$ en absoluto, puesto que esto, es decir, la aplicación de cualquier nombre, lo haría participar del número $\mathrm{y}$, por tanto, de lo que es.

La importancia de esta analítica del no-ser radica en que es aquí donde se construye la noción absoluta o existencial del no-ser que, erigida como contraria del ser, el sofista asocia a la falsedad y a la imagen (240a). El resto del diálogo buscará, justamente, desmontar tal asociación, haciendo del no-ser no lo contrario del ser, sino algo diferente de él. Es esta concepción relativa del no-ser la que le permitirá a Platón quitarse de encima la noción absoluta que tornaba ininteligibles a estos conceptos. Sobre lo contrario del ser, aquello que veremos operando en el Eutidemo, el Extranjero llega finalmente a la conclusión (259a) de que no podemos afirmar que exista o no. Sobre ello, si es que realmente podemos referirlo, sólo sería posible guardar silencio.

\section{II}

Aunque es el Extranjero de Elea quien expone estas dificultades, éste sólo opera como portavoz de la posición del sofista (236c-d y 239c). Pero el Sofista no es la única obra en la cual Platón pone argumentos como los analizados en boca de personajes que reciben esta calificación, ya que también es posible rastrearlos hasta el Eutidemo. En este apartado nos detendremos en la caracterización de los erísticos de este diálogo 
en tanto "sofistas". Para tal fin, primero haremos una presentación de estas figuras, delineando las características de su patrón argumentativo. Luego, nos ocuparemos de rastrear tales elementos en el Sofista, más específicamente, en la séptima definición.

Eutidemo y Dionisodoro son dos hermanos provenientes de Turios.

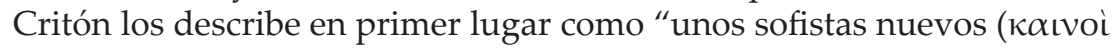

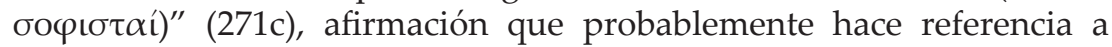
la experticia y cualidad de sabios de ambos, ya que luego pregunta a

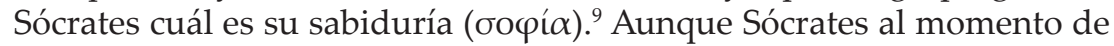
introducirlos en $271 \mathrm{c}-272 \mathrm{~b}$ pretende hacer de ellos hombres versados en la lucha física y judicial, en 273d los extranjeros se desentienden de estas actividades, presentándose sólo como maestros de virtud. Por supuesto, ninguno de los dos la entiende del mismo modo que los presentes, puesto que esta es identificada con la destreza argumentativa

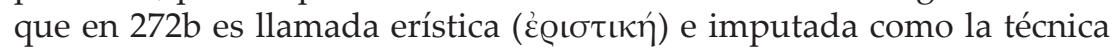

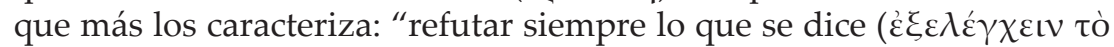

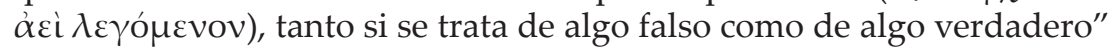
(Euthd. 272b).

La labor discursiva de los erísticos exhibe características muy particulares. A los fines de este trabajo, nos gustaría prestar atención a tres aspectos de ella. En primer lugar, los hermanos proponen un intercambio de tipo dialéctico, esto es, una conversación en la cual se dialoga exclusivamente a partir de preguntas precisas y respuestas breves mediante las cuales se elabora un argumento. El rol del erístico en la conversación, por su parte, siempre es el de preguntar, nunca el de responder. Como se puede apreciar en 275a-c, desde el principio los hermanos se posicionan como interrogadores y pocas veces en el diálogo ceden el control de la argumentación.

En segundo lugar, el propósito de los erísticos es refutar ( $\dot{\varepsilon} \xi \lambda \lambda \dot{\varepsilon} \gamma \chi \varepsilon เ v)$ al adversario, es decir, construir con sus respuestas un razonamiento que concluya algo contradictorio o incompatible con una tesis defendida previamente por él. Si, por ejemplo, Clinias sostiene que aprenden los que saben, lo interrogarán hasta hacerle afirmar que aprenden los que no saben (275d-276c). La refutación erística, además, no se preocupa ni por contenido ni por la verdad de lo que es refutado: su pretensión es que

9 Sobre el término $\sigma o \varphi \iota \sigma \tau \eta ́ s$, que en su origen no era despectivo y funcionaba como sinónimo бọós, designando a alguien considerado sabio, cfr. Grote (1850, pp. 479-485) y Guthrie (1969, pp. 38-45). 
el adversario sea refutado conteste lo que conteste y sea cual sea la tesis que intenta defender (275e). Esto es así porque los erísticos introducen a sus interlocutores en terrenos donde ya tienen argumentos preparados para atacar cada posición.

En tercer lugar, el recurso privilegiado para dar lugar a la refutación es la ambigüedad sintáctica o semántica, así como cualquier otro uso de lenguaje que habilite equívocos. Paradigmático de esta estrategia es el empleo que hacen en $275 \mathrm{~d}-276 \mathrm{c}$ del verbo $\mu \alpha v \theta \alpha \dot{v} v \varepsilon เ v$, que puede significar tanto "aprender" como "comprender". Pasándole inadvertido esto a Clinias, los erísticos lo refutan en cuatro oportunidades, haciéndole sostener de modo sucesivo que: $(a)$ aprenden los sabios; $(b)$ aprenden los ignorantes; $(c)$ los que aprenden aprenden lo que saben; $(d)$ los que aprenden aprenden lo que no saben. La facilidad con la cual los erísticos se sirven de estos argumentos se debe a que imponen reglas estrictas al interrogado, el cual debe limitarse a responder por "sí" o por "no", sin que sea posible repreguntar o introducir aclaraciones (295b-296c).

No hay acuerdo sobre la filiación de esta forma de argumentación. Algunos especialistas defienden sus raíces en el movimiento sofístico del siglo $\mathrm{V}$ a. $\mathrm{C}$. Otros sostienen que tras la erística se escondería el grupo megárico. Hay quienes, finalmente, toman como un dato que se trataría de "sofistas". ${ }^{10}$ Dado el fin propuesto, esta será nuestra actitud en este trabajo, ya que, por un lado, Eutidemo y Dionisodoro son llamados "sofistas", tanto directa (271c) como indirectamente (277e, 288 b y 297c); por otro, incluso si estos términos no aparecieran en el Eutidemo, la práctica argumentativa que ostentan puede ser vinculada con al menos dos definiciones del Sofista. Puesto que el vínculo de los erísticos con la quinta ya ha sido tematizado, ${ }^{11}$ nos concentraremos en la

10 Para una ubicación de los erísticos en la tradición de sofistas del siglo $\mathrm{V}$ a. C., cfr. Kent Sprague (1972, pp. 294-295), Kerferd (1981, p. 53), Nehamas (1989) y Canto (1989, pp. 26-33). Para la hipótesis megárica, cfr. Hawtrey (1984, pp. 2330), Dorion (2000), Mársico e Inverso (2012, pp. 42-58) Gardella (2013) y Villar (2015). Representantes de la última actitud son Narcy (1984), Chance (1992) y Sermamoglou-Soulmadi (2014).

11 Cfr. Hitchcock (2000, pp. 61-62), Narcy (2013, pp. 64-67) y Villar (2016, pp. 196-204). 
séptima, aquella que, en rigor, constituye el cumplimiento del propósito del diálogo. ${ }^{12}$

Al finalizar la última definición, el sofista es caracterizado como un

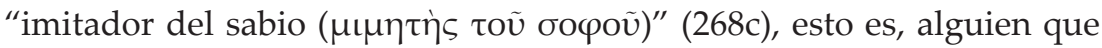
aparenta ser sabio sin serlo. Como ya vimos, su técnica es un tipo de

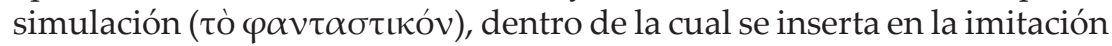

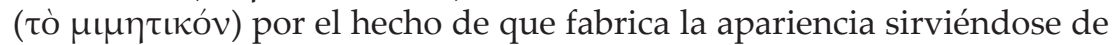
su cuerpo como instrumento. Lo propio del sofista es, además, el ser un farsante, ya que tiene conciencia de su falta de saber, algo que lo distingue del imitador que efectivamente conoce lo imitado como del ingenuo que imita lo que meramente cree saber. No obstante, ninguna de las siete divisiones empleadas para dar con este resultado preliminar coloca al sofista en una práctica intelectual concreta y específica. Es la última la que, en efecto, lo encierra en un ámbito discursivo próximo al del Eutidemo.

La división final separa dos actividades que se diferencian en base a su ámbito de aplicación, el medio del cual se sirven y el destinatario. La primera, cuyo cultor será llamado "orador popular"

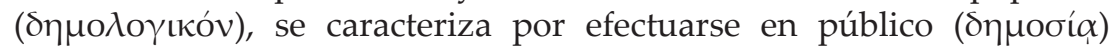

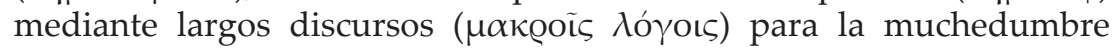
( $\pi$ @ò $\tau \lambda \eta \dot{\theta} \theta$ ). La otra, en cambio, se desarrolla en privado (ióí $\alpha$ )

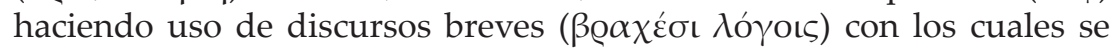

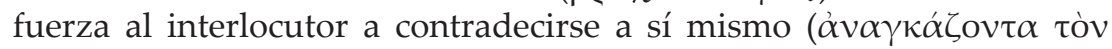

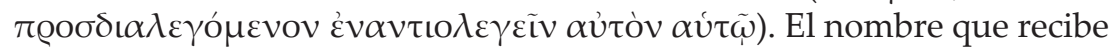

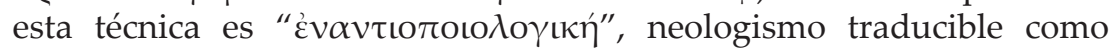
"técnica de producción de contradicciones". Es aquí donde finalmente colocan al sofista en $268 \mathrm{~d}$, lo cual, por su parte, guarda gran coherencia con el inicio de esta definición (232a-233d), que comenzó delineando al

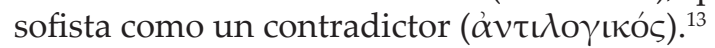

Los elementos de esta última división concuerdan con algunos rasgos de los erísticos del Eutidemo. Por un lado, la indicación de la brevedad podría tomarse como una especificación de su proceder dialéctico, más si tenemos en cuenta que en la quinta definición (225b) el fraccionamiento

12 En este punto seguimos a Rickless (2010), quien defiende que la última definición del sofista invalida que las seis anteriores puedan ser tomadas como genuinas definiciones.

13 Para un análisis completo de la séptima definición, cfr. Cornford (1935, pp. 323-331) y Sayre (2006, pp. 67-72). 
del discurso en preguntas y respuestas se opone a la extensión $(\mu \eta \dot{\kappa} \kappa$ $\lambda o ́ \gamma(\omega v)$. Por otro lado, el rol de interrogador del sofista está sugerido por su objetivo: contradecir a su adversario. En efecto, suponiendo que estamos frente a una situación dialéctica, sólo extrayendo respuestas del adversario se lo podría obligar a admitir algo contra su posición. Esta actitud interrogativa está, además, reforzada por Sofista 239d-240a, donde el Extranjero indica que deben hallar una respuesta para oponer a las preguntas del sofista y advierte sobre el hecho de que, lejos de contentarse con sus definiciones, este continuará preguntando sobre lo que se obtiene de sus dichos.

Consideramos que alcanza con lo antedicho para sostener que Eutidemo y Dionisodoro podrían efectivamente considerarse dos sofistas, al menos en el sentido que este término adquirió a partir del Sofista, que es, además, el que privilegiará la tradición, sobre todo Aristóteles en Refutaciones sofísticas. ${ }^{14}$ En lo que sigue analizaremos de qué modo Platón retrató en el Eutidemo a dos sofistas haciendo uso de argumentos que, en muchos de los supuestos y nociones que emplean, evocan la posición que el Extranjero de Elea imputa al sofista en su intento de evadir la séptima definición.

\section{III}

La sección del Eutidemo que analizaremos se ubica inmediatamente después del primer protréptico (278e-283b), en el cual Sócrates concluye junto a Clinias que hay que volverse lo más sabio posible, mostrando así cómo debe hacerse un discurso exhortativo. Una vez finalizado, Sócrates vuelve a pedir a los hermanos que inciten a Clinias a la filosofía y la virtud, ya que todos sus amigos desean que éste se vuelva sabio y bueno. Es Dionisodoro el que toma la palabra, preguntando si están bromeando al explicitar ese deseo. Ante la falta de retractación, el erístico elabora en $283 \mathrm{c}-\mathrm{d}$ un razonamiento en cuatro pasos que, justamente, tiene al no-ser como noción fundamental.

Después de establecer que los presentes "desean que él se vuelva

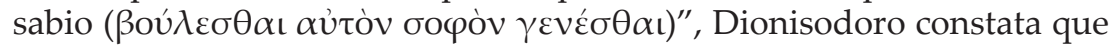

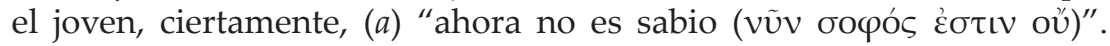

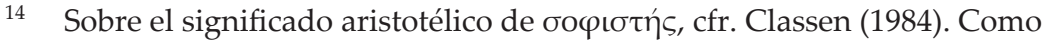
indicamos en la nota 10, el valor semántico de este término no era ni específico ni peyorativo antes de Platón. Para un estudio de los usos platónicos más allá del Sofista y cómo este fue construyendo su propia noción, cfr. Corey (2015). 
Siguiendo las alternativas férreas que los erísticos emplean desde la primera demostración (276b), esta afirmación equivale a "ahora es ignorante", con lo cual, luego le hace admitir a Sócrates que $(b)$ "quieren

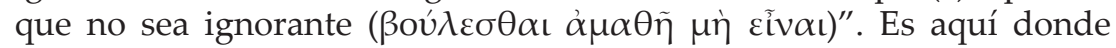
Dionisodoro dará el movimiento clave, ya que una vez aceptado esto, concluye que (c) "quieren que él se vuelva lo que no es (ôs $\mu \varepsilon \grave{v}$ oủk

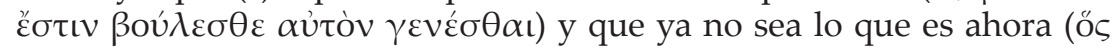
$\delta$ ' que tenga tiempo para procesarlas, son rematadas con lo siguiente: $(d)$

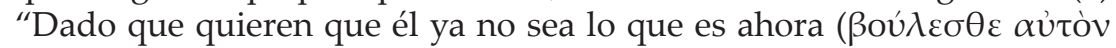

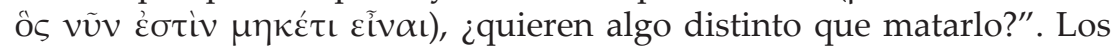
amigos de Clinias, al parecer, desean su destrucción.

Las palabras que emplea Dionisodoro son complejas y no están exentas de ambigüedades. Dado que Clinias no es sabio, el sofista

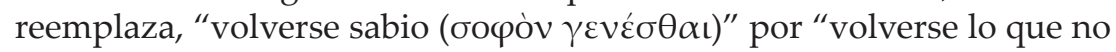

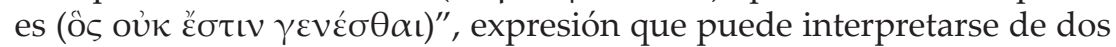
maneras. En efecto, el verbo čotıv de la construcción con pronombre relativo podría poseer valor copulativo y conectar al sujeto -elidido en este caso- con el pronombre, el cual estaría en lugar de la cualidad que éste no posee. Pero Dionisodoro sigue la vía de la otra lectura, en la cual

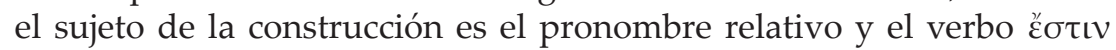
posee valor existencial. Así, por tanto, el erístico concluye que desean

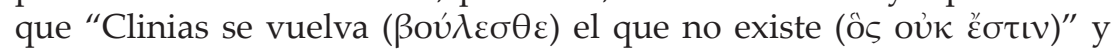
que "ya no exista ( $\mu \eta \kappa \varepsilon ́ \tau \iota ~ \varepsilon i ̃ v \alpha \iota)$ el que existe ahora (ő $\delta$ ' interpretaciones de عĩv $\alpha$ เ que se vuelven evidentes sólo al ser vinculadas con la muerte del joven. ${ }^{15}$

En este prólogo a lo que vendrá ya puede apreciarse que los sofistas están instalados en la equivocidad semántica y sintáctica que afecta al ser y al no-ser. En el resto de la demostración se encargarán de desplegar,

15 Hay quienes interpretan que en el argumento interviene la confusión entre una atribución relativa y una absoluta (cfr. Aristóteles, Ref. Sof. 5.167a ss.), a saber, entre "no ser ignorante" y "no ser" (cfr. Kent Sprague, 1962, p. 13 y Hawtrey, 1984, p. 3). Aunque este podría ser un ingrediente del argumento, nuestra explicación es la que mejor recoge que la confusión de Sócrates se introduzca exactamente donde es visible la ambigüedad del cĩv $\alpha$. Igualmente, acordamos con Chance (1992 pp. 11-13 y 85-86) en que querer reducir los argumentos erísticos a un único elemento es un error, especialmente visible en este ejemplo. 
mediante tres complejos argumentos, distintas aristas problemáticas de estas nociones, las cuales recuerdan el tratamiento del problema de la falsedad en el Sofista. En lo que sigue los analizaremos detalladamente, procurando ver, por un lado, su formulación, funcionamiento y contenido filosófico; por otro, el contexto dramático en el cual cada uno es introducido.

\section{No es posible mentir (283e-284a)}

Es Ctesipo, el enamorado de Clinias, quien reacciona violentamente frente al argumento de Dionisodoro, acusándolo de mentir ( $\kappa \alpha \tau \alpha \psi \varepsilon v ́ \delta \varepsilon \iota)$

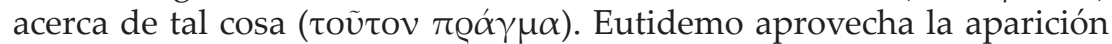
del término $\kappa \alpha \tau \alpha \psi \varepsilon u ́ \delta \varepsilon \sigma \theta \alpha \mathrm{L}$, que menta propiamente el acto de difamar a otro, para preguntarle a Ctesipo si le parece que es posible mentir (oíov

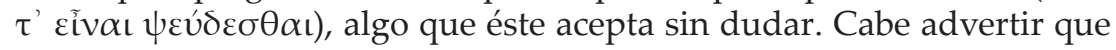
el término griego $\psi \varepsilon v ́ \delta \varepsilon \sigma \theta \alpha \iota$ coparte raíz con $\psi \varepsilon \tilde{v} \delta o \varsigma$ y $\psi \varepsilon v \delta \tilde{\eta}$, palabras que en el Sofista se usaban para referir a la falsedad y a las cosas falsas respectivamente. Si bien este verbo incluye el matiz de una voluntad de engaño al decir falsedades, el argumento que Eutidemo construirá se centra sólo en las condiciones veritativas del discurso. ${ }^{16}$

En primer lugar, Eutidemo hace afirmar a Ctesipo que se miente (a)

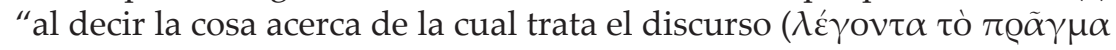

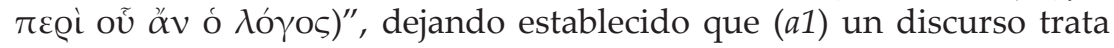
sobre una cosa $(\pi \varrho \tilde{\alpha} \gamma \mu \alpha)$ y que, además, (a2) dice ( $\lambda \dot{\gamma} \gamma \varepsilon t v)$ esa cosa. El segundo movimiento vincula a esta última con el ser, apelando a tres pasos que van de la pluralidad -las cosas que son- a la unidad -lo

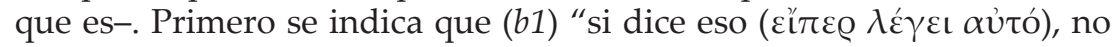

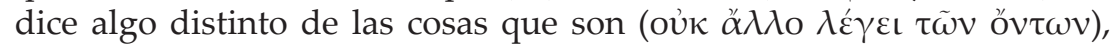

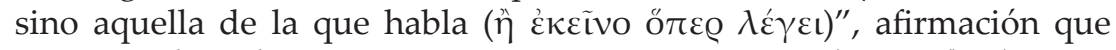
se acota aún más, aclarando que (b2) "eso que dice ( $\dot{\kappa} \kappa \varepsilon$ เvo ô $\lambda \dot{\varepsilon} \gamma \varepsilon \iota$ ) es

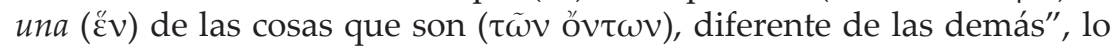
cual finalmente da lugar a que (b3) "el que la dice, dice lo que es (ó

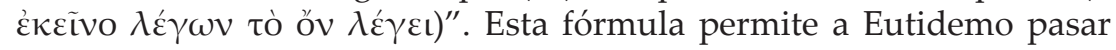

16 En el Sofista Platón imputa al sofista la intención de engañar (268a). Sin embargo, su tratamiento se concentra solo en la falsedad que ello implicaría. El Eutidemo tampoco problematiza ese aspecto, sino que el argumento se centra únicamente en que mentir constituye decir falsedades. Para la inclusión de la condición de insinceridad en el campo semántico que rodea a la falsedad, cfr. Chantraine (1968, pp. 1287-1288). 
rápidamente de "lo que es" a "la verdad", indicando que $(c)$ "el que dice lo que es, es decir, las cosas que son, dice la verdad ( $\tau \dot{\alpha} \lambda \eta \theta \tilde{\eta} \lambda \dot{\varepsilon} \gamma \varepsilon \iota)$ ". Si Dionisodoro dice la verdad, entonces no está mintiendo.

Los supuestos sobre los que descansan estas premisas son conocidos para nosotros, ya que reproducen varias de las consideraciones del Sofista en torno a la falsedad, aunque mostrando, en este caso, la imposibilidad de ella a través de la necesidad de la verdad de cualquier discurso. ${ }^{17} \mathrm{Si}$ en la primer aporía sobre el no-ser (Sofista 237b-237e) se negaba que un decir que no fuera sobre algo -el cual debía ser uno y existente- fuera un genuino decir, el argumento de Dionisodoro saca las consecuencias positivas de esto: cuando alguien dice, debe decir una cosa $(\pi \varrho \tilde{\alpha} \gamma \mu \alpha), \mathrm{y}$ esa cosa estará entre las que son, con lo cual, apelando al reverso de la caracterización de la falsedad como "decir lo que no es", decir una cosa que es es decir la verdad.

Para la mayoría de los intérpretes la clave del argumento está en la transición entre las premisas $a$ y $b$, más específicamente, en cómo debe

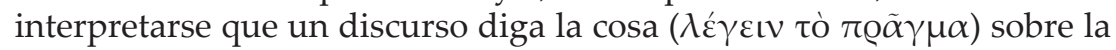
cual él versa. De acuerdo con la lectura de Crombie (1963, pp. 488-489), los sofistas toman esta expresión como si significara que un discurso nombra $(\lambda \varepsilon \dot{\gamma} \gamma \iota v)$ un hecho o estado de cosas $(\pi \varrho \tilde{\alpha} \gamma \mu \alpha)$, el cual debe existir para que el decir tenga referencia y no sea mero ruido. Esto último es lo que le ocurriría al discurso falso, ya que el hecho que debería designar no existe..$^{18}$ Esta sugerencia guarda un vínculo estrecho con la dificultad de Sofista 237b-237e: lo que allí estaba en discusión era si "lo que no es" puede considerarse un nombre (övo $\mu \alpha$ ) aplicable a algo, lo cual, como vimos, no era posible. Esta refutación apela a supuestos similares, ya que coloca como condición del decir el que este deba remitir a una cosa existente.

17 El argumento reproduce casi textualmente la posición antisténica transmitida por Proclo en Sobre el Crátilo de Platón 37: "El que dice dice algo, el que dice algo dice lo que es, y el que dice lo que es dice la verdad". Sobre la presencia de Antístenes en el Eutidemo, cfr. Mársico e Inverso (2012, pp. 66-72).

18 La oración "El pasto es verde" sería sobre el-pasto-siendo-verde, hecho nombrado por ella. Pero "El pasto es rojo" sería sobre el-pasto-siendo-rojo, el cual, dado que no existe, no puede ser referido. Esta lectura y ejemplos de Crombie son desarrollados muy pormenorizadamente por Denyer (1993, pp. 8-23). 
De todos modos, esta interpretación supone más elementos que los que la refutación de Dionisodoro realmente utiliza, ya que en ella

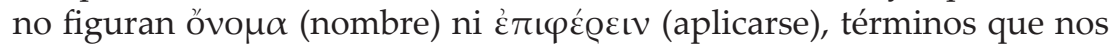
instalarían en un marco designativo estricto. Tampoco estamos forzados a interpretar que $\pi \varrho \tilde{\alpha} \gamma \mu \alpha$ remite a alguna realidad compleja, como un hecho o estado de cosas. Creemos que si el argumento funciona es porque se maneja en un ámbito de gran indeterminación, facilitado por las expresiones poco transparentes que emplea, principalmente " $\lambda \varepsilon ́ \gamma \varepsilon \iota v$ tò $\pi \varrho \tilde{\alpha} \gamma \mu \alpha$ ", que puede significar tanto "hablar acerca de una cosa" como "decir una cosa", siendo $\pi \varrho \tilde{\alpha} \gamma \mu \alpha$, además, un término vago y poco específico, como lo era el " $\tau \iota^{\prime}$ empleado en el Sofista. ${ }^{19}$ La fórmula

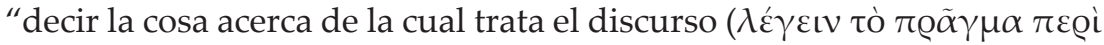
oũ ăv ó $\lambda o ́ \gamma o \varsigma) "$ compromete a Ctesipo con un supuesto peligroso si se lo acepta sin aclarar su significado: que un discurso versa sobre una cosa. Aunque jamás se determine qué es esa cosa, la admisión es suficiente para que Dionisodoro lo encierre en la premisa $b$, donde se establece que aquello que el discurso dice está entre las cosas existentes. El pasaje del sentido existencial de عĩv $\alpha$ เ al veritativo terminará soldando el discurso y la verdad.

\section{No es posible decir lo que no es (284b-c)}

No satisfecho con este resultado, Ctesipo insistirá en la mentira de Dionisodoro, replicando que "el que dice esas cosas (ó $\tau \alpha \tilde{v} \tau \alpha \lambda \dot{\varepsilon} \gamma \omega v)$ ", a saber, que quieren matar a Clinias, "no dice las cosas que son (oủ

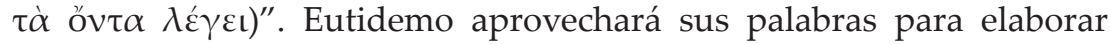
un argumento complementario al anterior, en tanto que "no decir las cosas que son" será para él equivalente a "decir las cosas que no son", lo cual, como mostrará con su interrogatorio, nadie sería capaz de hacer. Si antes había demostrado que es necesario decir la verdad, ahora establecerá, como en el Sofista, que es imposible decir algo falso. ${ }^{20}$ La refutación consta de seis premisas que, a su vez, pueden dividirse en dos líneas argumentales que se ensamblan en la conclusión. Una $(a-c)$

19 Cfr. Canto (1989, p. 199, n. 109), Chance (1992, p. 87) y Mársico e Inverso (2012, pp. 133-134).

${ }_{20}$ Crombie (1963, p. 488) y Denyer (1993, pp. 8-9) consideran que los argumentos son parte de uno único, algo que no permite apreciar su especificidad: el primero versa sobre lo que es, el segundo sobre lo que no es. 
prueba que "nadie puede producir lo que no es", la otra ( $d-f)$ que "hablar es producir".

Respecto del primer punto, Eutidemo deja sentado que (a) "las

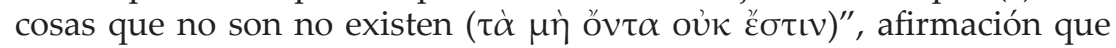
se refuerza indicando que $(b)$ "no existen de ningún modo (oủ $\delta \alpha \mu \tilde{v})$ ". Luego hace admitir a Ctesipo dos supuestos que, aunque distintos, considera dependientes el uno del otro. En efecto, pregunta primero si (c1) "es posible que alguien haga algo acerca de las cosas que no son ( inmediatamente $(c 2)$ "de manera que pudiera producir esas cosas que

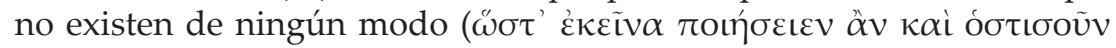

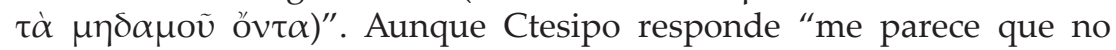

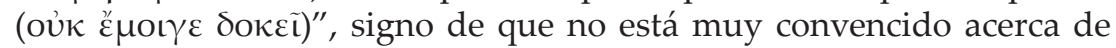
la cuestión, con ello dio su asentimiento a la implicación entre "hacer algo acerca de las cosas que no son (

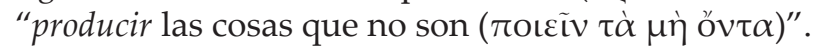

En cuanto al segundo punto, Eutidemo inquiere sobre si $(d)$ "los

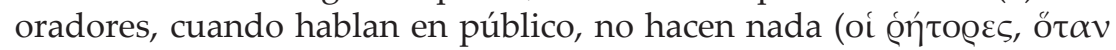

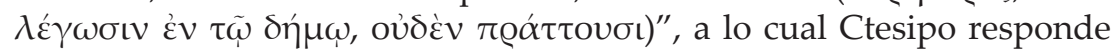

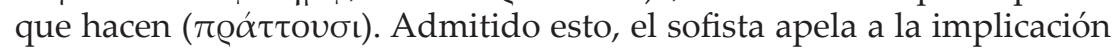
entre "hacer" y "producir" establecida antes y le hace afirmar que $(e)$ "si

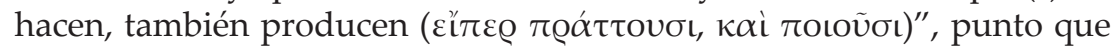
le permite retomar la acción de hablar de los oradores para concluir que

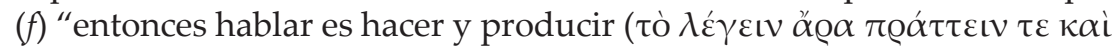

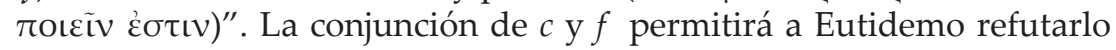

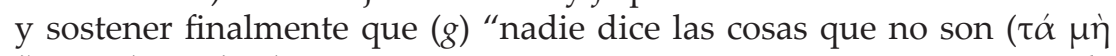

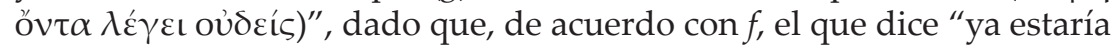

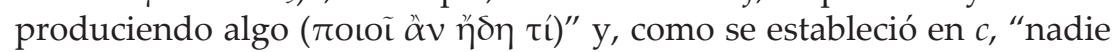
puede producir lo que no es ( Invocando otra vez la equivalencia entre lo que no es y lo falso, el sofista

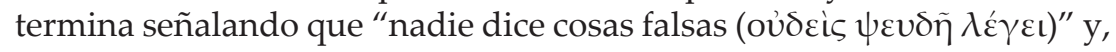
por tanto, Dionisodoro dice la verdad.

Las premisas $a, b$ y $c$ son las que traen a escena la noción absoluta del no-ser que vimos operando en el Sofista, la cual, por su parte, ya había sido introducida en el argumento sobre la muerte de Clinias. El paso $b$ es el que más recuerda a "lo que no es de ningún modo ( ya que luego de afirmar que lo que no es no existe, este punto se enfatiza indicando que no existe "de ninguna manera ( $\mu \eta \delta \alpha \mu o \tilde{v})$ ". Aunque el adverbio $\mu \eta \delta \alpha \mu$ ov suele ser leído como una indicación temporal -“en 
ningún lugar"-, algunos especialistas defienden su carácter netamente modal, lectura que se impone si prestamos atención a que el pasaje quiere destacar que lo que no es no existe bajo distintas modalidades, ya sea como objeto de acción, producción o lenguaje. ${ }^{21}$

La diferencia entre estos tres ámbitos será borrada en las premisas

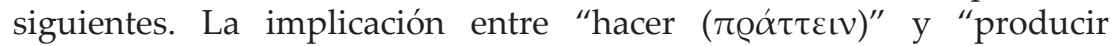
$(\pi \mathrm{O} \varepsilon \tilde{\varepsilon} v)$ " casi no recibe justificación en $c$, lo que explicaría la cautela de Ctesipo. Igualmente, la intención de Eutidemo parece que es

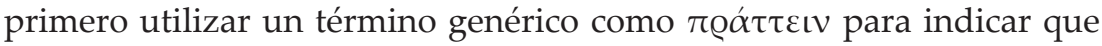
no es posible "actuar" o "hacer cualquier cosa" respecto de lo que no es y luego concretizar dicho supuesto en una acción concreta como la producción. Los pasos subsiguientes justamente apelan a un ejemplo donde esta transformación opera sin margen de dudas: el orador, al hablar, realiza una acción, la cual, además, tiene un producto evidente, sea este el discurso mismo o su contenido. ${ }^{22}$ Hablar, entonces, es actuar y producir algo que debe existir, ya que lo que no es no existe y no puede ser objeto de producción.

Lo que permite la refutación es la conjunción entre una noción de producción ligada a lo que es y la concepción del decir como un producir,

$21 \quad$ Este matiz es defendido por De Vries (1972, p. 47), Denyer (1993, p. 9) y Mársico e Inverso (2012, p. 135). El resto de los especialistas traduce $\mu \eta \delta \alpha \mu$ v como adverbio de tiempo. La única defensa de esta interpretación la realiza Chance (1992, p. 89), quien argumenta que la palabra tiene una contraposición positiva en $c$, cuando se afirma que los oradores hablan "ante el público" ( $\dot{\varepsilon} v \tau \tilde{\omega}$ $\delta \eta \dot{\mu}(\omega)$. Si lo que no es no existe en ningún lugar, la acción de los oradores sí, lo cual reforzaría que no se pueda decir lo que no es. La elección entre uno u otro sentido no vulnera el hecho de que el argumento funciona gracias a una noción existencial de no-ser, aunque nuestra interpretación torna más visible el paralelo con el Sofista.

22 Algunos comentadores del Eutidemo sugieren que el argumento se sirve ante todo de la confusión entre el discurso y su contenido (cfr. Méridier, 1931, p. 162; Canto, 1989, p. 200, n. 110 y Sermamoglou-Soulmadi, 2014, p. 77). No obstante, consideramos que Eutidemo nunca sugiere que se está refiriendo más al discurso que al contenido de este al afirmar que un orador realiza algo. Creemos que, en todo caso, deja indeterminada la cuestión al vincular el decir con producir "algo $(\tau \iota)$ " en $284 c 4$. Por lo demás, en caso de que se distinguiera claramente entre el $\lambda o ́ \gamma o \varsigma$ y aquello sobre lo cual él versa, el sofista podría apelar a lo establecido en la refutación anterior y defender que eso también debe estar entre las cosas existentes. 
supuestos que impiden que sea posible dar cuenta de cualquier contacto lingüístico con el no-ser absoluto. Ambas ideas también tienen claros ecos en el Sofista. Por un lado, el producir es conceptualizado en Sofista $219 \mathrm{~b}$ en términos de "cuando alguien lleva a ser todo aquello que antes

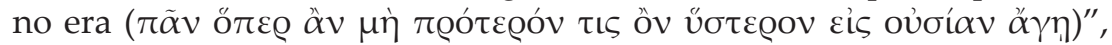
definición que se repite en $265 \mathrm{~b}$. Por otro lado, la labor lingüística del sofista, como vimos, es englobada desde el inicio de la última definición en la técnica productiva (233d), algo sobre lo cual se insiste a lo largo del proceso definicional y que daba lugar a la paradoja, que surgía justamente al acusar al sofista de producir lo que no es mediante el discurso. $^{23}$

\section{No es posible contradecir (285d-286b)}

La respuesta de Ctesipo a esta refutación buscará complejizar el vínculo entre falsedad y no-ser, aclarando que en un discurso falso "las cosas que son se dicen de una cierta manera, no realmente como son $(\tau \dot{\alpha}$

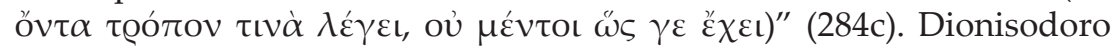
se servirá de esto para extraer la idea de que hay algunos, los veraces,

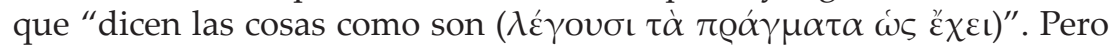
dado que las cosas malas son malas y los grandes son grandes, entonces

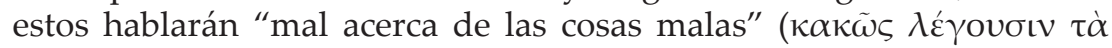

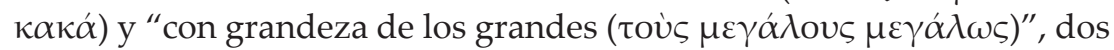

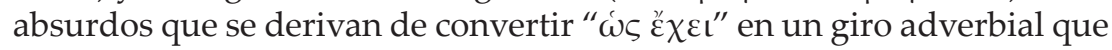
ya no refiere al objeto del discurso, como seguramente creía Ctesipo, sino a la acción subjetiva del hablante, influenciada por las cualidades del primero.

La tensión del diálogo en este punto aumenta tanto que Sócrates debe intervenir para evitar las ofensas mutuas. Ctesipo, de todos modos, aclara que no está enfadado y que no ha ofendido al sofista, como este afirma en $284 \mathrm{e}$, sino que sólo contradice ( $\dot{\alpha} \nu \tau \iota \lambda \dot{\varepsilon} \gamma \varepsilon เ v)$ lo que le parece que no está bien dicho. La mención de la contradicción será tomada por Dionisodoro instantáneamente para imputar a su interlocutor que habla

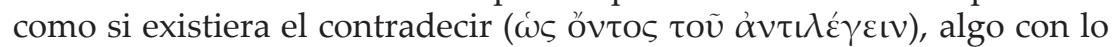
cual este acuerda e intenta defender mediante respuestas pragmáticas, como que en este momento él mismo lo está contradiciendo. Dionisodoro

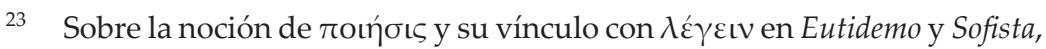
cfr. Marcos (2000, pp. 148-151). 
prescinde de cualquier apelación a los hechos, sosteniendo que Ctesipo jamás podrá mostrar $(\dot{\alpha} \pi 0 \delta \varepsilon i ́ \xi \alpha \iota \varsigma)$ que ha escuchado a dos personas contradecirse. Como en el Sofista, la afirmación de la existencia de algo habilita la pregunta por su explicación, y es allí donde surgirán los problemas.

La refutación involucra tres pasos. En primer lugar, luego de dejar

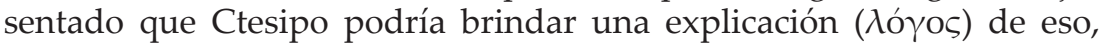
esto es, de que él está contradiciendo a Dionisodoro, el sofista explotará la mención al $\lambda$ ó $\gamma$ os para hacerle establecer que $(a)$ "hay enunciados

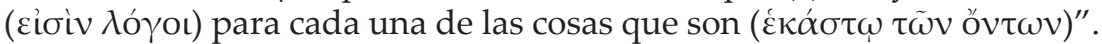
A este supuesto se le añade que tales enunciados son $(b)$ "respecto de

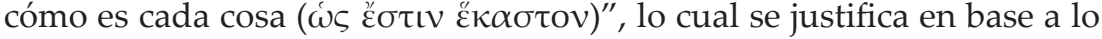
establecido antes, donde quedó probado que nadie dice algo como no es y que no es posible manifestar lo que no es al hablar. Aunque Ctesipo no entiende cómo esto afectaría el que ellos se están contradiciendo, ha admitido dos supuestos peligrosos.

El tercer paso extraerá la imposibilidad de la contradicción a partir de la presentación de tres situaciones que distribuirían de modo exhaustivo los roles entre quienes discuten en torno a una misma cosa y pretenden enunciar cómo ella es. En primer lugar, no se contradirían (c1) "cuando

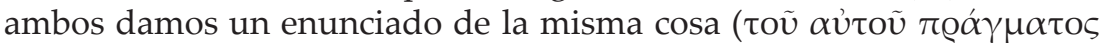

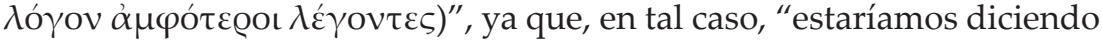
lo mismo ( $\alpha \hat{v} \tau \alpha \hat{\tau} \tau \dot{\alpha} \lambda \hat{\varepsilon} \gamma \mathrm{o} \mu \varepsilon v)$ ). Aquí es necesario detenerse en el significado de $\lambda$ ó $\gamma o \varsigma$, el cual hemos traducido por "enunciado". Aunque los especialistas no acuerdan en cómo volcar el término en este contexto, ${ }^{24}$ todos interpretan que el $\lambda$ ó $\gamma \mathrm{s}$ al cual se refiere Dionisodoro no es cualquier $\lambda$ ó $\gamma$ os que corresponda a la cosa, sino aquel que dice exactamente cómo es, el cual se supone único y exclusivo de ella. Si, entonces, para cada cosa hay un enunciado que dice cómo es, los que dan ese enunciado deben decir las mismas palabras, siendo, por tanto, imposible que se contradigan. ${ }^{25}$

24 Chance (1992, p. 99) traduce "account"; Mársico e Inverso (2012, p. 140), “explicación”; Kent Sprague (1962, p. 17), “description”; SermamaglouSoulmadi (2014 p. 79), "proper description"; Canto (1989, p. 136), "énoncé"; Denyer (1993, p. 16), "speech"; Crombie es poco claro y oscila entre "statement" y "account".

25 La explicación más clara de esta lectura clásica del argumento la realiza Chance (1992, pp. 98-100). 
La segunda posibilidad señala que (c2) "cuando ninguno de los

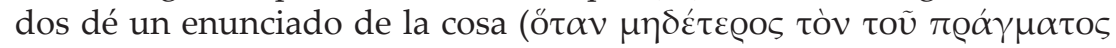

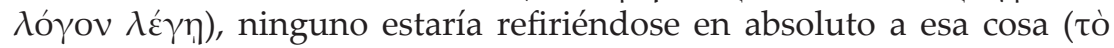

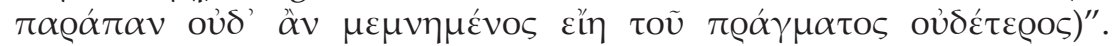
Nótese que de no dar el enunciado de la cosa y decir cómo es, se juzga que ni siquiera se hizo mención ( $\mu \mu \nu \eta ́ \sigma \kappa \varepsilon \sigma \theta \alpha \iota)$ de ella, ya que, como se estableció, ningún enunciado puede mostrar lo que no es. La última situación cierra las posibilidades, postulando que (c3) "cuando yo doy un enunciado de una cosa, y tú das otra de una distinta (ö $\alpha \alpha \nu$ غ̇ $\gamma \hat{\omega}$

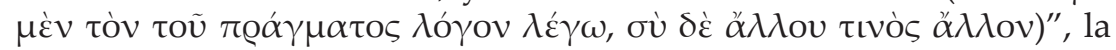
contradicción tampoco resulta, debido a que "yo digo la cosa, mientras

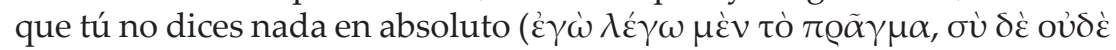

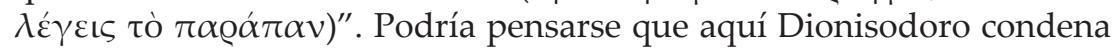
al sinsentido al interlocutor, lo cual se refuerza en que luego afirma

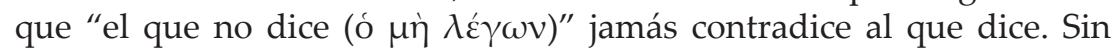
embargo, es claro que la segunda persona dice otro enunciado ( $\alpha$ $\lambda \lambda$ ov),

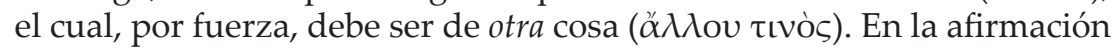
final, entonces, debe leerse que este no dice nada respecto de la cosa del primer hablante, aunque sí diga algo.

Según la interpretación tradicional de esta refutación, en ella opera el supuesto de que, dado que hay un único enunciado que dice cómo es cada cosa, dos personas que den el enunciado de una misma cosa, dirán "las mismas cosas ( $\tau \dot{\alpha} v \tau \alpha$ )", expresión que habría que leer como "las mismas palabras". En efecto, esta lectura se impone si atendemos a que en tal caso habría una única formula lingüística -sea esta del tipo que sea, esto es, o un nombre, o una descripción, o un discurso más complejo, etc.- que indique cómo es cada cosa. Sin embargo, nos permitiremos aquí dudar de que el argumento realmente se funde en la unicidad del $\lambda o ́ \gamma o \varsigma$, al menos por dos razones.

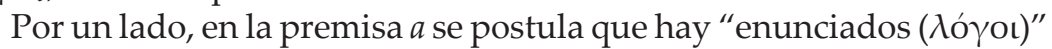
para cada una de las cosas que son, plural que no sugiere una relación uno a uno entre enunciado y cosa. Por otro, en ninguno de los tres pasos de $c$ el sustantivo $\lambda$ ó $\gamma$ os es modificado por un artículo o adjetivo que indique unicidad, especificidad o mismidad de la expresión lingüística empleada para expresar el $\pi \varrho \alpha ́ \gamma \mu \alpha$. La fórmula utilizada siempre

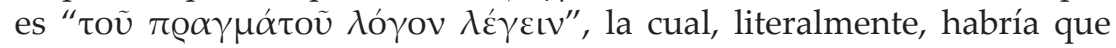
traducir como "decir un enunciado de la cosa". Dada la noción de $\lambda$ ó $\gamma o \varsigma$ fijada en la premisa $b$, decir un $\lambda$ ó $\gamma$ os de una cosa será siempre decir lo que es respecto de ella y, por consiguiente, la verdad. No es necesario 
que el enunciado sea el mismo para que la refutación funcione, sino que

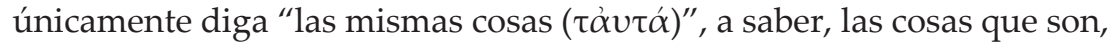
algo que, ciertamente, la sección entera maneja como condición de todo genuino decir. ${ }^{26}$

El silencio de Ctesipo al finalizar el argumento marca el éxito de la refutación, que ha logrado ligar el decir de cada uno de los interlocutores de una discusión a una cosa distinta, acerca de la cual, además, o se da un enunciado que dice de ella lo que es y la verdad, o no se la refiere en absoluto. Sin ir por los mismos caminos que la argumentación del Sofista, donde se probaba la imposibilidad de dar explicación de la falsedad, la ausencia de contradicción es el corolario necesario de hacer de todo decir un discurso verdadero. Es este nexo necesario que se construye entre el $\lambda o ́ \gamma o \varsigma$ y lo que es lo que coloca a esta refutación final dentro de los supuestos sobre los que descansa la argumentación de toda esta sección del Eutidemo y lo analizado en el Sofista.

\section{IV}

La tercera refutación provocará la intervención de Sócrates, quien luego de permanecer como mero espectador, buscará en 286c-288c cambiar el eje de la discusión, intentando que los hermanos se hagan cargo de las consecuencias indeseables de su posición. En efecto, si no es posible decir falsedades ni equivocarse en nada, lo cual haría que nadie fuese ignorante, ¿por qué afirman ser sabios y capaces de enseñar? ¿Cómo pueden, asimismo, pedir que los refuten respecto de estos puntos si es imposible contradecir? ¿En virtud de qué, por último, se burlan de su interlocutor cuando lo refutan si no es precisamente porque contesta erróneamente? El veredicto de Sócrates es sugestivo: la posición de los sofistas es realmente extraña y asombrosa, ya que sostener la imposibilidad de la falsedad anula las bases mismas de su práctica intelectual.

26 La unicidad del $\lambda$ ó ${ }^{2}$ os que incluyen aquí los especialistas es un influjo de la teoría del oíkeĩos $\lambda$ ó $\gamma$ os de Antístenes. El paralelo de este argumento con la posición del socrático ha sido marcado expresamente por Méridier (1931, pp. 129-130), Canto (1989, p. 57 y 91), Denyer (1993, pp. 27-33), Mársico e Inverso (2012, pp. 66-72) y Gardella (2013, pp. 58-62). Aunque no negamos la influencia antisténica, nuestra intención es únicamente señalar que el argumento logra su cometido incluso haciendo uso de menos elementos teóricos. 
El Eutidemo, sin embargo, no trasciende este tipo de respuestas pragmáticas al argumento, las cuales, si bien ponen en jaque a los sofistas y señalan en la dirección de que no podrían estar en lo cierto, jamás ponen en entredicho los supuestos sobre los que descansa la paradoja. Esto último es lo que se propone el Sofista, el cual no sólo se ocupa de enunciarla, sino también, como vimos, de explicitar sus nociones fundamentales, lo cual constituye un paso ineludible para poder desmontarlos, tarea que Platón emprenderá por primera vez en este diálogo. Como indicamos, tal empresa implica una revisión de la noción de no-ser empleada por los sofistas: si estos se esconden detrás de un no-ser absoluto, Platón mostrará que existe otra posibilidad de conceptualizar lo que no es, no ya como lo contrario del ser, algo inexistente y perdido tanto para el pensamiento como para el lenguaje, sino diferente de lo que es.

El otro ingrediente de la solución platónica al problema, a saber,

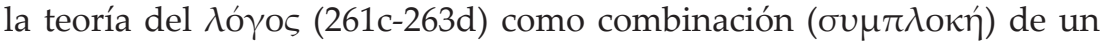
nombre (óvo $\mu \alpha)$ y un verbo (@́ñ $\mu \alpha)$, refuerza el vínculo entre el Eutidemo y el Sofista. Tal como sostuvimos, si los argumentos de los erísticos logran su cometido es porque se manejan en un gran nivel de indeterminación conceptual, principalmente respecto del objeto que debe operar como correlato de un genuino decir, referido en el Eutidemo a partir del poco específico término " $\pi \varrho \alpha ́ \gamma \mu \alpha$ ", que opera como paralelo del "algo" ( $\tau \mathrm{L})$ del Sofista. Es el hecho de concebir eso sobre lo cual versa el discurso como algo existente, sin aclarar exactamente de qué se trata, uno de los componentes que allana el camino hacia la paradoja.

En el Sofista Platón barrerá con esta imprecisión, haciendo del discurso una realidad compleja que, en tanto enuncia "algo acerca de algo", ya no dice sólo o bien "cosas que son" o bien "cosas que no son", última alternativa que, por juzgarse imposible, reducía la falsedad al hablar vacío. Conceptualizar la verdad en términos de enunciar "cómo es" el referente de un nombre y la falsedad, por el contrario, en "cómo no es", entendiendo con esto último no lo inexistente, sino aquello que es distinto de lo que es, constituye, ciertamente, el intento platónico de abandonar la ausencia de claridad que rodeaba a los argumentos sofísticos, los cuales, como hemos defendido, estaban completamente instalados en la equivocidad de todas las nociones en juego. 


\section{Bibliografía}

Bossi, B. (2013). Back to the Point: Plato and Parmenides - Genuine Parricide? En B. Bossi y T. Robinson (eds.), Plato's Sophist revisited. (pp. 157-173). Berlín: De Gruyter.

Burnet, J. (1995). Platonis Opera I. Oxford: Oxford University Press.

Canto, M. (1989). Platon. Euthydème. París: Flammarion.

Chance, T. (1992), Plato's Euthydemus: Analysis of What Is and Is Not Philosophy. Berkeley-Los Angeles: University of California Press.

Chantraine, P. (1968). Dictionnaire Étymologique de la langue grecque. Histoire des mots. París: Klincksieck.

Classen, C. J. (1979). Aristotle's Picture of the Sophists. En G. B. Kerferd (ed.), The Sophists and Their Legacy. (pp. 7-24). Wiesbaden: Franz Steiner Verlag Gmbh.

Corey, D. (2015). The Sophists in Plato's Dialogues. Albany: State University of New York Press.

Cordero, N. (1988). Platón. Sofista. Madrid: Gredos. (2005). Siendo, se es. La tesis de Parménides. Buenos Aires: Biblos.

Cornford, F. M. (1935). Plato's Theory of Knowledge. Londres: Routledge y Kegan Paul.

Crombie, I. M. (1963). An Examination of Plato's Doctrines. Vol. II. Londres: Routledge y Kegan Paul.

De Vries, G. J. (1982). Notes on Some Passages in the Euthydemus. Mnemosyne, 25, 42-55.

Denyer, N. (1991). Language, Thought and Falsehood in Ancient Greek Philosophy. Londres-Nueva York: Routledge.

Dorion, L. A. (2000). Euthydème et Dionysodore sont-ils des Mégariques? En T. Robinson y L. Brisson (eds.), Plato. Euthydemus, Lysis, Charmides. Proceedings of the V Symposium Platonicum. (pp. 3550). Sankt Augustin: Academia Verlag.

Gardella, M. (2013). Conflictos socráticos en el Eutidemo: la crítica platónica a la dialéctica megárica. Argos. Revista de la Asociación Argentina de Estudios Clásicos, 36, 45-64.

Grote, G. (1850). History of Greece. Volume 8. Cambridge: Cambridge University Press.

Guthrie, W. K. C. (1969). Historia de la filosofía griega III. Siglo V. Ilustración. Madrid: Gredos. 
Hawtrey, R. (1981). Commentary on Plato's Euthydemus. Filadelfia: American Philosophical Society.

Hitchcock, D. (2000). The Origin of Professional Eristic. En T. Robinson y L. Brisson (eds.), Plato. Euthydemus, Lysis, Charmides. Proceedings of the V Symposium Platonicum. (pp. 59-67). Sankt Augustin: Academia Verlag.

Kahn, C. (2003). The Verb 'Be' in Ancient Greek. Cambridge: Hackett.

Kent Sprague, R. (1962). Plato's Use of Fallacy. Nueva York: Barnes \& Noble.

(1972). The Older Sophists. Indianapolis: Hackett Publishing Company.

Kerferd, G. B. (1981). The Sophistic Movement. Cambridge: Cambridge University Press.

Lidell, H. G., Scott, R. y Jones, H. S. (1996). A Greek-English Lexicon. Oxford: Clarendon Press.

Marcos, G. E. (1995). Platón ante el problema del error. Buenos Aires: Fundec.

(2000). Las falacias en torno a la falsedad. Una lectura de Eutidemo 283e-286b a la luz de la solución del Sofista. En T. Robinson y L. Brisson (eds.), Plato. Euthydemus, Lysis, Charmides. Proceedings of the $V$ Symposium Platonicum. (pp. 144-153). Sankt Augustin: Academia Verlag.

Mársico, C. e Inverso, H. (2012). Platón. Eutidemo. Buenos Aires: Losada. Méridier, L. (1931). Platon: Ion, Ménexène, Euthydème. París: Les Belles Lettres.

Narcy, M. (1984). Le philosophe et son doublé. Un commentaire de l'Euthydème de Platon. París: Vrin.

(2013). Remarks on the First Five Definitions of the Sophist (Soph. 221c - 235a). En B. Bossi y T. Robinson (eds.), Plato's Sophist revisited. (pp. 57-70). Berlín: De Gruyter.

Nehamas, A. (1989). Eristic, Antilogic, Sophistic, Dialectic: Plato's Demarcation of Philosophy from Sophistry. History of Philosophy Quarterly, 7(1), 3-16.

Notomi, N. (1999). The Unity of Plato's Sophist. Cambridge: Cambridge University Press.

O'Brien, B. (2013). Does Plato refute Parmenides? En B. Bossi y T. Robinson (eds.), Plato's Sophist revisited. (pp. 117-155). Berlín: De Gruyter. 
Rickless, S. (2010). Plato's Definition(s) of Sophistry. Ancient Philosophy, 30(2), 289-298.

Sayre, K. (2006). Metaphysics and Method in Plato's Statesman. Nueva York: Cambridge University Press.

Sermamoglou-Soulmadi, G. (2014). Playful Philosophy and Serious Sophistry. Berlín-Boston: De Gruyter.

Sonna, V. (2017). Ouk éstin antilégein: Antístenes tras las máscara de Parménides en el Sofista de Platón. Eidos, 27, 15-38.

Villar, F. (2016). Los megáricos como sofistas erísticos. La respuesta platónica al ataque de Isócrates contra los socráticos. Eidos, 25, 185213. 
